\title{
Monilófitas da Estação Ecológica do Panga, Uberlândia, Estado Minas Gerais, Brasil: Dennstaedtiaceae, Dryopteridaceae, Gleicheniaceae, Hymenophyllaceae e Lindsaeaceae
}

\author{
Adriana A. Arantes ${ }^{1,3}$, Jefferson Prado ${ }^{1}$ e Marli A. Ranal ${ }^{2}$
}

Recebido: 14.12.2007; aceito: 14.08.2008

\begin{abstract}
Monilophytes of the Ecological Station of Panga, Uberlândia, State of Minas Gerais, Brazil: Dennstaedtiaceae, Dryopteridaceae, Gleicheniaceae, Hymenophyllaceae, and Lindsaeaceae). This paper provides the taxonomic treatment for the Monilophytes focuses on Dennstaedtiaceae, Dryopteridaceae, Gleicheniaceae, Hymenophyllaceae, and Lindsaeaceae of the Ecological Station of Panga. This Ecological Station covers an area of 409.5 hectares and is sited about $30 \mathrm{Km}$ to the south of the city of Uberlândia, Minas Gerais State, Brazil, between the geographical coordinates $19^{\circ} 09^{\prime} 20^{\prime \prime}-19^{\circ} 11^{\prime} 10^{\prime \prime} \mathrm{S}$ and $48^{\circ} 23^{\prime} 20^{\prime \prime}-48^{\circ} 24^{\prime} 35^{\prime \prime} \mathrm{W}$, at 740 to $840 \mathrm{~m}$. The area is one of the few of the region with natural vegetation, with different savannah physiognomies and forest formations. One species of Dennstaedtiaceae (Pteridium arachnoideum (Kaulf.) Maxon), Gleicheniaceae (Dicranopteris flexuosa (Schrad.) Underw.), and Hymenophyllaceae (Trichomanes cristatum Kaulf.) and two species of Dryopteridaceae (Elaphoglossum perelegans (Fée) T. Moore, E. scalpellum (Mart.) T. Moore) and Lindsaeaceae (Lindsaea pallida Klotzsch., L. quadrangularis Raddi) were found. Identification key, descriptions, illustrations of diagnostic characters of the species, geographical distribution, and comments are presented.
\end{abstract}

Key words: "Cerrado", ferns, flora, monilophytes

RESUMO - Monilófitas da Estação Ecológica do Panga, Uberlândia, Estado de Minas Gerais, Brasil: Dennstaedtiaceae, Dryopteridaceae, Gleicheniaceae, Hymenophyllaceae e Lindsaeaceae). O presente trabalho apresenta o tratamento taxonômico das espécies de Dennstaedtiaceae, Dryopteridaceae, Gleicheniaceae, Hymenophyllaceae e Lindsaeaceae da Estação Ecológica do Panga. A Estação Ecológica do Panga abrange 409,5 ha, e está situada a $30 \mathrm{~km}$ ao sul da cidade de Uberlândia, MG, entre as coordenadas $19^{\circ} 09^{\prime} 20^{\prime \prime}-19^{\circ} 11^{\prime} 10^{\prime \prime} \mathrm{S}$ e $48^{\circ} 23^{\prime} 20^{\prime \prime}-48^{\circ} 24^{\prime} 35^{\prime \prime} \mathrm{W}$, a $740-840 \mathrm{~m}$ de altitude. A área é uma das poucas formações de vegetação natural da região e possui diferentes fisionomias do Cerrado e florestais. Uma espécie de Dennstaedtiaceae (Pteridium arachnoideum (Kaulf.) Maxon.), Gleicheniaceae (Dicranopteris flexuosa (Schrad.) Underw.) e Hymenophyllaceae (Trichomanes cristatum Kaulf.) e duas espécies de Dryopteridaceae (Elaphoglossum perelegans (Fée) T. Moore, E. scalpellum (Mart.) T. Moore) e Lindsaeaceae (Lindsaea pallida Klotzch., L. quadrangularis Raddi) foram encontradas. São apresentadas chaves para as famílias e espécies, bem como ilustrações, distribuição geográfica e comentários de todos os táxons.

Palavras-chave: Cerrado, flora, monilófitas, samambaias

\section{Introdução}

O termo pteridófitas é usado para indicar as samambaias e plantas afins, englobando dois grandes grupos de plantas vasculares sem sementes, as licófitas e monilófitas (Pryer et al. 2004). As pteridófitas constituem um grupo bastante heterogêneo que cresce e vive em vasta gama de regiões e ambientes, apresentando uma diversidade morfológica bastante acentuada e correspondentes adaptações para os variados hábitats (Windisch 1992).
Mais recentemente, Smith et al.(2006) propuseram um novo sistema de classificação para as monilófitas subdividindo-as em quatro classes (Psilotopsida, Equisetopsida, Marattiopsida e Polypodiopsida) e 11 ordens monofiléticas, sendo que das 37 famílias consideradas pelos autores, 32 são fortemente suportadas como monofiléticas.

Com base na literatura, estima-se que existam entre 10.000 a 11.300 espécies diferentes de pteridófitas no mundo (Roos 1996), das quais cerca de 3.000 ocorrem na América do Sul (Tryon \& Tryon 1982,

1. Instituto de Botânica, Seção de Curadoria do Herbário, Caixa Postal 3005, 01061-970 São Paulo, SP, Brasil

2. Universidade Federal de Uberlândia, Instituto de Biologia, Caixa Postal 593, 38400-902 Uberlândia, MG, Brasil

3. Autor para correspondência: adrianassisa@ hotmail.com 
Moran 1995a), sendo 30\% deste montante, de 1.200 a 1.300 espécies, encontradas em território brasileiro (Prado 2007).

As regiões Sul e Sudeste contêm mais da metade das espécies que ocorrem no Brasil (cerca de 800 espécies) e abrigam um dos centros de endemismo e especiação de pteridófitas no Continente SulAmericano (Tryon 1986, Prado 2007). Essas espécies distribuem-se principalmente nas regiões montanhosas e cobertas de Floresta Atlântica e de vegetação associada (Prado 2007).

Para Minas Gerais são estimadas cerca de 50\% do total das espécies brasileiras (Salino 2000). Elas ocorrem em maior proporção nas regiões de floresta ombrófita, como na serra da Mantiqueira e na porção sul da Cadeia do Espinhaço (Ouro Preto, Caraça e Belo Horizonte), assim como em área do interior do estado em regiões que apresentam mosaicos de florestas ombrófitas e semideciduais (Parque Estadual do Rio Doce e Estação Biológica de Caratinga) (Salino 2000). Por outro lado, a riqueza florística de pteridófitas também é elevada no bioma Cerrado (Mendonça et al. 1998), principalmente nos campos rupestres do estado de Minas Gerais, com altas taxas de endemismo. Contudo, é necessário ter em mente que ainda faltam inventários florísticos detalhados para grande parte do Brasil, além de poucas coleções e uma real falta de dados quando se procura escolher uma região adequada para estudos florísticos (Meira Neto 2003).

A região do Triângulo Mineiro, onde está situada a Estação Ecológica do Panga, é considerada como uma das mais críticas, por restarem poucos remanescentes do bioma Cerrado e poucas unidades de proteção integral (Drummond et al. 2005). A E. E. do Panga tem sido bem preservada desde $1985 \mathrm{em}$ função de inúmeros estudos relativos à flora e fauna que ali são desenvolvidos, o que lhe deu o status de área de alta preservação (Drummond et al. 2005). A pteridoflora desta área está constituída por 52 espécies, 15 famílias e 22 gêneros. Thelypteridaceae é a mais rica entre as samambaias, com 14 espécies e dois gêneros (Arantes et al. 2007a, b, 2008), seguida de Pteridaceae e Polypodiaceae com quatro gêneros e sete espécies cada.

\section{Material e métodos}

A Estação Ecológica do Panga (E. E. P.) abrange 409,5 ha e está situada a $30 \mathrm{~km}$ ao sul do centro da cidade de Uberlândia, MG, entre as coordenadas $19^{\circ} 09^{\prime} 20^{\prime \prime}-19^{\circ} 11^{\prime} 10^{\prime}$ " S e $48^{\circ} 23^{\prime} 20^{\prime}$ '- 48 $24^{\circ} 35^{\prime}$ ' W, a 740-840 m de altitude (Araújo et al. 2002). A área apresenta fisionomias comuns do bioma Cerrado como campestres (Campo Sujo, Campo Limpo Úmido), savânicas (Cerrado sentido restrito, Veredas) e florestais (Cerradão, Mata seca e Mata de galeria) (Ribeiro \& Walter 1998).

Os espécimes testemunhos foram coletados, herborizados e depositados nos Herbários HUFU, da Universidade Federal de Uberlândia, MG, e SP, do Instituto de Botânica, SP.

As chaves para as famílias e as descrições das espécies foram elaboradas com base nos caracteres morfológicos dos espécimes coletados na área e, quando necessário, complementadas com material de áreas próximas. As descrições das famílias e gêneros foram elaboradas com base nas características contidas na literatura como em Smith et al. (2006) e Moran (1995b, c, d). A terminologia morfológica adotada está de acordo com Lellinger (2002). As abreviações dos nomes dos autores de táxons seguiram Pichi-Sermolli (1996). O tratamento taxonômico está apresentado em ordem alfabética dos táxons encontrados na área de estudo.

\section{Resultados e Discussão}

$\mathrm{Na}$ área de estudo foram encontradas 15 famílias e 52 espécies de samambaias e licófitas, sendo aqui tratados apenas os representantes das famílias Dennstaedtiaceae, Dryopteridaceae, Gleicheniaceae, Hymenophyllaceae e Lindsaeaceae.

\section{Chave para as famílias}

1. Plantas com lâmina foliar com 1-2 camadas de células em espessura, membranácea; indúsio tubular Hymenophyllaceae

1. Plantas com lâmina foliar com mais de duas camadas de células em espessura, cartácea a coriácea; indúsio ausente ou presente, nunca tubular

2. Lâmina inteira; soros acrosticóides Dryopteridaceae

2. Lâmina pseudodicotomicamente dividida ou 1-4-pinada, pinatífida, pinatissecta ou pectinada; soros não acrosticóides 
3. Lâmina pseudodicotomicamente dividida, com gemas latentes nas bifurcações; indúsio ausente Gleicheniaceae

3. Lâmina não pseudodicotomicamente dividida, sem gemas latentes nas bifurcações; indúsio conspícuo ou vestigial

4. Lâmina 1-2(-4)-pinada, pinas e/ou pínulas dimidiadas; soros lineares, sub-marginais; indúsio linear, conspícuo Lindsaeaceae

4. Lâmina 1-4-pinado-pinatífida, pinas e pínulas pinado-pinatífidas, pinatífidas a pinatissectas; soros lineares, marginais; indúsio abaxial vestigial, falso indúsio formado pela margem recurvada da lâmina Dennstaedtiaceae

Dennstaedtiaceae Lotsy, Vortr. Bot. Stammesgesch. 2: 655.1909.

Plantas terrestres, epífitas, rupícolas, raramente arborescentes. Caule ereto a horizontal, geralmente longoreptante, sifonostélico ou polistélico, com escamas e/ou tricomas. Frondes eretas ou escandentes, monomorfas ou raramente dimorfas; pecíolo com mais de três feixes vasculares na base, sulcado, sulcos contínuos ou não, podendo apresentar gemas epipeciolares; lâmina 1-4pinado-pinatífida, raramente simples, pilosa ou glabra, raramente com escamas; raque sulcada; nervuras livres, furcadas ou pinadas, raro anastomosadas e, neste caso, sem vênulas inclusas. Soros marginais ou submarginais; indúsio cupuliforme, inconspícuo ou ausente, neste caso com um falso indúsio formado pela margem recurvada da lâmina; esporângios pedicelados, pedicelos com 1-3 fileiras de células, ânulo vertical e interrompido no pedicelo; esporos aclorofilados, tetraédricos, triletes e monoletes.

Família com distribuição pantropical, com poucos representantes ocorrendo nas Regiões Boreal e Sul Temperada (Tryon \& Tryon 1982). Pertencem a esta família ca. 11 gêneros e 170 espécies (Smith et al. 2006). Com a exclusão de Lindsaeaceae e a inclusão de representantes de Hypolepidaceae, Monachosoraceae e Pteridiaceae, o grupo dennstaeditióide pode ser considerado monofilético (Pryer et al. 2004). Uma única espécie desta família foi encontrada na E. E. do Panga, Pteridium arachnoideum (Kaulf.) Maxon.

Pteridium Gled. ex Scop., Fl. Carn. 169. 1760, nom. cons. Tipo: Pteris aquilina L. (三 Pteridium aquilinum (L.) Kuhn).

Plantas terrestres. Caule horizontal, longoreptante, sem escamas, com tricomas. Frondes monomorfas; pecíolo com gemas e tricomas na base; lâmina 1-4-pinado-pinatífida, coberta por tricomas ou glabra, coriácea, deltóide ou pentagonal, sem gemas nas axilas das pinas; pinas ou pínulas pinado-pinatífidas, subopostas a alternas, pecioluladas, ocasionalmente com nectários nas axilas; nervuras livres, simples a furcadas. Soros marginais, contínuos ou interrompidos, formados sobre uma comissura vascular que une os ápices das nervuras; soros lineares, marginais, abrigados por um falso indúsio formado pela margem recurvada da lâmina e às vezes por um indúsio abaxial, membranáceo, inconspícuo, extrorso; esporângios glabros, com ânulo vertical ou levemente oblíquo; paráfises ausentes; esporos triletes, castanhos, verrucosos.

Pteridium é um gênero cosmopolita, com ca. 12 espécies. Embora Tryon \& Tryon (1982) tenham considerado apenas uma espécie dividida em 12 variedades, algumas dessas são claramente distintas e merecem reconhecimento em nível específico (Moran 1995b, Mickel \& Smith 2004).

As plantas deste grupo são geralmente invasoras agressivas, ocorrendo com freqüência em áreas alteradas (Mickel \& Smith 2004).

Pteridium arachnoideum (Kaulf.) Maxon, J. Wash. Acad. Sci. 14: 89. 1924 = Pteris arachnoidea Kaulf., Enum. Filic.: 190. 1824. Tipo: Brasil, Chamisso s.n. (LE, n.v.).

Caule 8-10 mm diâm., com tricomas setiformes e septados, 2-4 mm compr., castanho-claros. Frondes 85-178 cm compr.; pecíolo 21-58 ×0,4-0,6 cm, sulcado adaxialmente, castanho-escuro e piloso próximo à base, glabro na porção distal, tricomas setiformes semelhantes aos do caule e aciculares, 1-2 mm compr., castanho-claros; lâmina 80-120 × 40-150 cm, deltóide, 4-pinado-pinatífida na base a 1-pinado-pinatífida no ápice, coriácea, adaxialmente glabrescente ou esparsamente pilosa, com tricomas aciculares, septados, 0,02-0,05 mm compr., amarelados, face abaxial tomentosa, tricomas aciculares e/ou septados, hialinos; raque e raquíola pubescentes, não aladas, com tricomas septados, 0,02-0,05 mm compr., castanho-claros; pinas 9-75 × 4-62 cm, lanceoladas, 
2-pinado-pinatífidas basalmente, pinatífidas a pinatissectas no ápice, alternas a subopostas, sésseis a pecioluladas, peciólulos, 0,1-11 cm compr.; pínulas inteiras a 1-pinado-pinatífidas, lanceoladas, alternas a subopostas; segmentos inteiros, crenados, pinatífidos ou pinatissectos, oblongos a lanceolados, 0,3-13,5 cm compr.; raquíola de segunda ordem com lobos presentes ao menos entre os últimos segmentos; nervuras livres, simples a 1-2-furcadas. Soros lineares, marginais; indúsio abaxial vestigial, pseudo-indúsios lineares, margens erodidas.

Material examinado: BRASIL. Minas Gerais: Uberlândia, Estação Ecológica do Panga, V-1992, M.A. Ranal 591 (HUFU, SP); IV-1999, M.A. Ranal 654 (HUFU, SP); VII-1999, M.A. Ranal 776 (HUFU, SP), M.A. Ranal 793 (HUFU, SP); XI-1999, M.A. Ranal 991 (HUFU, SP).

Pteridium arachnoideum ocorre em áreas abertas e alteradas, de 100- $2.450 \mathrm{~m}$ altitude; desde o México e Mesoamérica às Antilhas, Colômbia, Venezuela, Trindade, Guiana, Suriname, Guiana Francesa, Equador, Peru, Brasil, Bolívia, Paraguai, Argentina e Uruguai (Mickel \& Smith 2004). Na E. E. Panga foram coletados materiais em campo úmido e na mata de galeria, além do seu registro no banco de esporos de coletas de casca de árvores (Ranal 2003). A espécie é reconhecida pelas frondes grandes, lâminas coriáceas, com margens marcadamente revolutas que simulam um falso indúsio e lobos na raquíola de segunda ordem.

Dryopteridaceae Herter., Rev. Sudam. Bot. 9: 15. 1949.

Plantas terrestres, rupícolas ou epífitas. Caule ereto a horizontal, curto a longo-reptante, com escamas não clatradas. Frondes monomorfas ou dimorfas; pecíolo glabro a escamoso, articulado ou não ao caule, com mais de três feixes vasculares na base em secção transversal; lâmina inteira, 2-pinada ou mais dividida, papirácea a coriácea, glabra, glandulosa, pubescente e/ou escamosa; nervuras livres, furcadas, pinadas ou anastomosadas, com ou sem vênulas inclusas nas aréolas. Soros circulares ou acrosticódes; indúsio presente ou ausente, peltado e arredondado ou basefixo e reniforme; esporângios glabros ou com tricomas no pedicelo, ânulo vertical interrompido pelo pedicelo; paráfises frequientemente ausentes; esporos aclorofilados, reniformes, monoletes.

Dryopteridaceae possui ca. 45 gêneros e aproximadamente 1.700 espécies, sendo que $70 \%$ delas pertencem aos gêneros Ctenitis (C. Chr.) C. Chr., Dryopteris Adans., Elaphoglossum Schott ex J.
Sm. e Polystichum Roth (Smith et al. 2006). A família tem distribuição Pantropical, com ampla distribuição na Região Neotropical, mas é no Leste da Ásia que apresenta maior diversidade (Tryon \& Tryon 1982).

Dryopteridaceae possui um longo histórico de revisões com relação à sua classificação. Dryopteridaceae s.l., como adotado por Smith et al. (2006), apresenta circunscrição mais ampla, incluindo famílias que antes eram segregadas, como é o caso de Elaphoglossaceae (Lomariopsidaceae). No entanto, algumas relações filogenéticas ainda permanecem incertas, principalmente no que se refere à inclusão de alguns gêneros como Didymochlaena, Hypodematium e Leucostegia.

Apesar da diversidade de caracteres, pode-se citar algumas características distintivas da família como frondes sulcadas adaxialmente, com sulcos contínuos entre si, com três ou mais feixes vasculares na base, esporos monoletes e $x=41$ (Moran 1995c, Smith et al. 2006).

Na E. E. do Panga, Dryopteridaceae está representada por duas espécies, Elaphoglossum perelegans (Fée) Moore e E. scalpellum (Mart.) Moore, ambas com lâmina foliar inteira.

Elaphoglossum Schott ex J. Sm., J. Bot. (Hooker) 4: 148. 1841, nom. cons. Tipo: Elaphoglossum conforme Schott ex J. Sm.

Plantas epífitas, terrestres ou rupícolas. Caule curto a longo-reptante, raro ereto, dorsiventral, com feixes vasculares ventrais alongados, com escamas claras a nigrescentes, basifixas ou peltadas, inteiras a dentadas, glabras ou ciliadas. Frondes simples e inteiras, raramente divididas, geralmente dimorfas; pecíolo articulado ou não ao caule por meio de um filopódio, glabro, com escamas e/ou com tricomas glandulares; lâmina inteira, ovada, oblanceolada a linear, papirácea a coriácea, glabra ou com escamas, geralmente diferentes das do caule e pecíolo, base arredondada a largamente atenuada, ápice acuminado, caudado a obtuso; costa sulcada adaxialmente, geralmente coberta por escamas semelhantes às do pecíolo; nervuras livres, raramente anastomosadas ou com uma nervura coletora submarginal, simples a 2-furcadas, terminando próximas às margens, sem formar hidatódios ou formando hidatódios conspícuos. Soros acrosticóides, cobrindo toda a face abaxial da fronde fértil; indúsio ausente; esporângios pedicelados, glabros, paráfises presentes ou não; esporos aclorofilados, bilaterais, monoletes.

Elaphoglossum caracteriza-se pelo caule reptante, com frondes inseridas dorsalmente e com raízes na face ventral, feixes vasculares ventrais alongados, 
lâmina simples e inteira, nervuras livres e soros acrosticóides (Moran 1995c). Aproximadamente 80\% das espécies possuem filopódios (meristelo) na porção basal do pecíolo (Moran 1995c), mas as espécies da E.E.P. não os apresenta.

O gênero possui distribuição pantropical a sul temperada, ocorrendo desde as Ilhas do Pacífico, Austrália, Nova Zelândia, mas com a maioria das espécies na América Tropical (Kramer 1990). São estimadas cerca de 600 espécies e destas, 450 são Neotropicais (Moran 1995c, Mickel \& Smith 2004). Comparando os caracteres morfológicos de Elaphoglossum e Lomariopsis, pensava-se que estes eram relacionados filogeneticamente; no entanto, as evidências moleculares não confirmaram tais relações. Por outro lado, Bolbitis parece estar mais próximo de Elaphoglossum (Mickel \& Smith 2004).

Chave para as espécies de Elaphoglossum da E. E. do Panga

1. Lâmina densamente escamosa nas duas faces e margens; escamas ovais, ciliadas, alaranjadas

E. perelegans

1. Lâminaesparsamenteescamosa,escamas somente na face adaxial e ausentes nas margens; escamas estreladas, castanhoclaras ou escuras E. scalpellum

Elaphoglossum perelegans (Fée) T. Moore, Ind. Fil.: 16. $1857 \equiv$ Acrostichum perelegans Fée, 2ième Mém. Foug.: 55, t. 23. 1845. Tipo: Brasil. Rio "Bucaina", Pohl 2099 (W, n.v.)

Figuras $1 \mathrm{~A}-\mathrm{C}$

Caule curto-reptante, ápice ereto, 8-10 mm diâm, com escamas lineares, ca. $1 \mathrm{~mm}$ compr., castanhoavermelhadas, unidas basalmente, inteiras. Frondes $36-44 \times 3,5-4,5 \mathrm{~cm}$, simples e inteiras, as férteis mais longas e estreitas; pecíolo 9-16 × 0,2-0,4 cm, não articulado ao caule, com escamas lanceoladas, alaranjadas, ciliadas, ca. 3,0 mm compr.; lâmina 22-31 $\times 3,5-4,5 \mathrm{~cm}$, oblanceolada, quando jovem densamente escamosa nas duas faces, na fase adulta com escamas presentes apenas nas margens, escamas até $1 \mathrm{~mm}$ compr., ovais, alaranjadas, ciliadas, diferentes das do caule, base atenuada, margens inteiras e escamosas, ápice acuminado a caudado; costa sulcada adaxialmente; nervuras livres, simples a 2-furcadas, com uma nervura coletora submarginal. Paráfises presentes.

Material examinado: BRASIL. Minas Gerais: Uberlândia, Estação Ecológica do Panga, III-1987,
M. A. Ranal 419 (HUFU, SP); IV-1992, M. A. Ranal 573 (HUFU).

Na E.E. do Panga a espécie foi coletada sobre barranco de voçoroca próximo ao Cerradão mesotrófico e em solo próximo à linha de drenagem, em mata de galeria.

Diferencia-se de Elaphoglossum scalpellum (Mart.) T. Moore pela presença marcante das escamas nas margens das lâminas (figura $1 \mathrm{~A}$ ), pelo maior tamanho de sua lâmina $(22-31 \times 3,5-4,5 \mathrm{~cm}$ vs. $10-16$ $\times 1,8-3,5 \mathrm{~cm})$ e a consistência cartácea das mesmas.

Elaphoglossum scalpellum (Mart.) T. Moore, Ind. Fil.: 14, 1857 = Acrostichum scalpellum Mart., Ic. Pl. Crypt. Bras.: 86. 1834. Tipo: Colômbia: Cerro de Araracuara, R. Yapurá, Martius s.n. (M, n.v.).

Figuras 1 D-G.

Plantas terrestres ou rupícolas. Caule curtoreptante, 5-10 mm diâm., densamente revestido por escamas, escamas até $5 \mathrm{~mm}$ compr., lineares, ferrugíneas, unidas basalmente, margens inteiras. Frondes 18-28 × 1,8-3,5 cm, simples e inteiras, as férteis maiores e mais estreitas; pecíolo 8-13 × 0,2-0,3 $\mathrm{cm}$, não articulado ao caule, sulcado, com escamas de até 5,0 mm compr., lineares, castanho-escuras; lâmina 10-16 × 1,8-3,5 cm, oblanceolada a elíptica, esparsamente escamosa na face adaxial, com escamas estreladas, de 1-3 mm compr., castanho-claras, base atenuada, ápice agudo a obtuso, margens inteiras e glabras; costa sulcada abaxialmente, com escamas estreladas, castanho-escuras; nervuras livres, com uma nervura coletora submarginal, simples a 2-furcadas. Paráfises presentes.

Material examinado: BRASIL. Minas Gerais: Uberlândia, Estação Ecológica do Panga, V-1992, M.A. Ranal 581 (HUFU, SP).

Esta espécie é pouco conhecida e coletada no Brasil (Alston 1958). Na E. E. do Panga foram encontrados poucos exemplares desta espécie crescendo sobre barranco de voçoroca e próximo ao cerradão.

Diferencia-se de Elaphoglossum perelegans pelo menor porte, $18-28 \mathrm{~cm}$ vs. $36-44 \mathrm{~cm}$, consistência coriácea da lâmina e, principalmente, pela presença de escamas estreladas (figura $1 \mathrm{~F}$ ), castanho-escuras, adaxialmente sobre a costa e ausência de escamas nas margens das lâminas.

Gleicheniaceae C. Presl, Reliq. Haenk. 1: 70. 1825. Gleichenieae R. Br., Prodr. Fl. Nov. Holl.: 160. 1810 . 

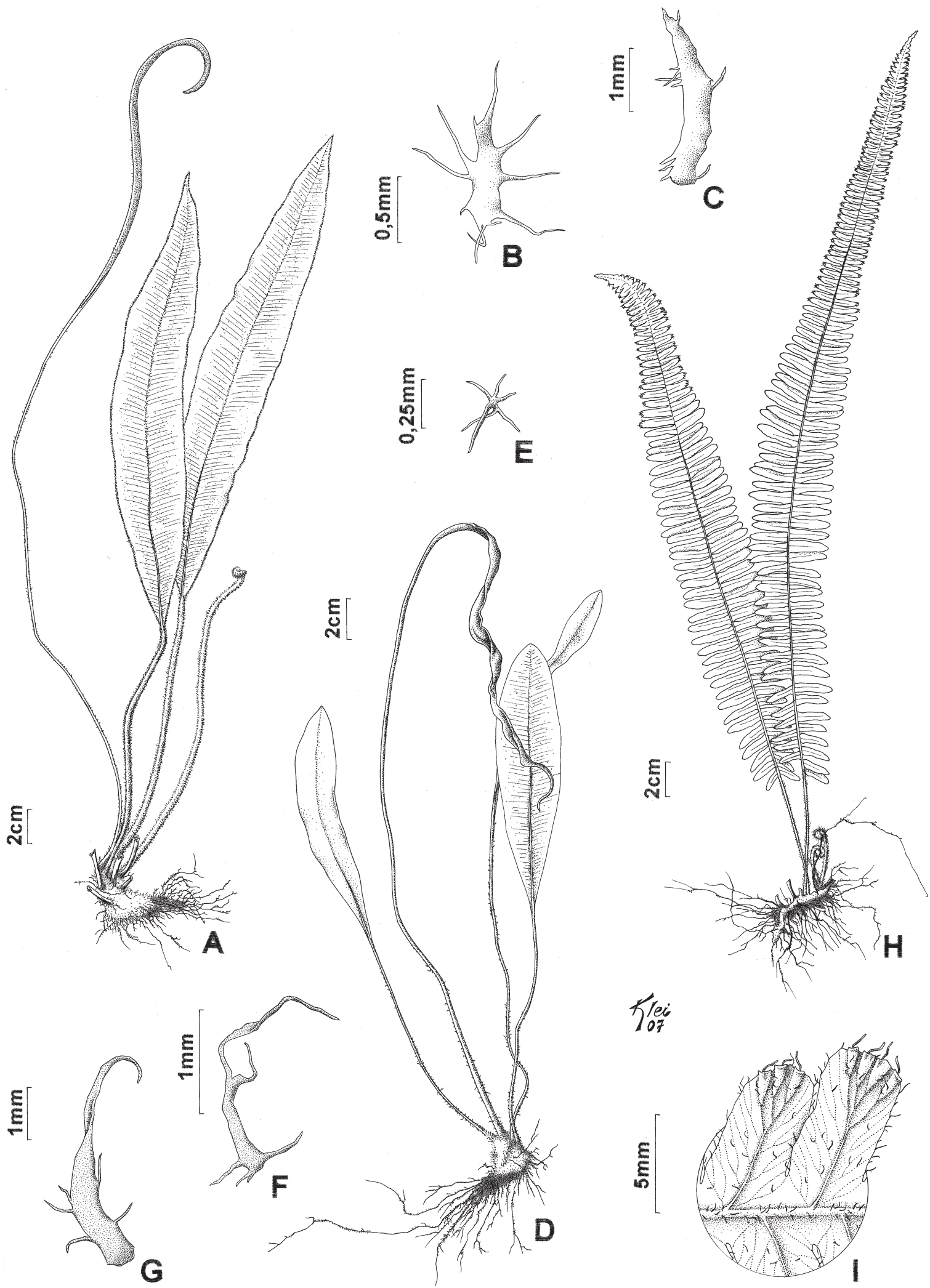

Figura 1. Espécies de Elaphoglossum e Trichomanes da Estação Ecológica do Panga, Minas Gerais, Brasil. A-C. Elaphoglossum perelegans (Ranal 573). A. Hábito. B. Escama do pecíolo. C. Escama da lâmina em face abaxial. D-G. Elaphoglossum scalpellum (Ranal 581). D. Hábito. E. Escama da lâmina em face abaxial. F. Escama da costa em face abaxial. G. Escama do pecíolo. H-I. Trichomanes cristatum (Ranal 386). H. Hábito. I. Detalhe da face abaxial da lâmina e indúsio tubular. 
Plantas terrestres. Caule horizontal, longoreptante, ramificado dicotomicamente, coberto por tricomas septados ou escamas. Frondes monomorfas, escandentes ou eretas, chegando a vários metros de comprimento devido ao crescimento indeterminado; pecíolo contínuo com o caule, com feixes vasculares na base em forma de "C" em corte transversal; lâmina pseudodicotomicamente dividida, com gemas nas bifurcações cobertas por tricomas ou escamas, em alguns casos protegidas por um par de pinas acessórias; pinas opostas, 2-pinado-pinatífidas ou mais vezes furcadas; nervuras livres, simples a 4-furcadas. Soros na face abaxial dos segmentos, inframedianos, arredondados, situados sobre as nervuras; indúsio ausente; esporângios glabros, agrupados em número de 2-25, globosos, subsésseis, com um ânulo oblíquo completo, com ou sem paráfises; esporos aclorofilados, amarelados, monoletes ou triletes.

De acordo com o sistema de classificação de Smith et al. (2006), a família é monofilética e inclui também os representantes das famílias Dicranopteridaceae e Stromatopteridaceae, anteriormente reconhecidas como táxons independentes. São reconhecidos seis gêneros, Dicranopteris Bernh., Diplopterygium (Diels) Nakai, Gleichenella Ching, Gleichenia Sm., Sticherus C. Presl, Stromatopteris Mett.. Gleicheniaceae possui distribuição pantropical, com cerca de 125 espécie. $\mathrm{Na}$ E. E. do Panga foi encontrada uma única espécie, Dicranopteris flexuosa (Schrad.) Underw.

Dicranopteris Bernh., Neues J. Bot. 1(2): 38. 1806. Lectótipo designado por Bernhardi, Neues J. Bot. 1(2): 38. 1806: Mertensia dichotoma (Thunb. ex Murray) Willd. ( $\equiv$ Dicranopteris dichotoma (Thunb. ex Murray) Bernh.)

Plantas terrestres. Caule longo-reptante, revestido por tricomas septados, aciculares. Frondes monomorfas, várias vezes furcadas, ramos da furca de tamanhos aproximados; pinas acessórias presentes na base da primeira pseudodicotomia; ramos basais das furcas sem segmentos pectinados; gemas protegidas por tricomas pluricelulares e por pseudo-estípulas; pinas 0-4 vezes furcadas, com ramificações de tamanhos iguais; últimos ramos pectinados e pinatífidos, glabros ou pilosos; nervuras livres, simples a 1-4 furcadas. Soros formados por 2-16 esporângios; paráfises ausentes; esporos triletes, raramente monoletes.

Dicranopteris é um gênero pantropical com cerca de 10 espécies, sendo que apenas quatro ocorrem na América (Mickel \& Smith 2004).

Dicranopteris flexuosa (Schrad.) Underw., Bull. Torrey Bot. Club 34: 254. 1907 = Mertensia flexuosa Schrad., Gött. Gel. Anz. 1824: 863. 1824.

Tipo: Brasil, von Wied-Neuwied s.n. (BR, n.v.)

Caule 3-5 mm diâm., dicotomicamente ramificado, coberto por tricomas septados, ca. 1,0 mm compr., avermelhados. Frondes $50-97 \mathrm{~cm}$ compr.; pecíolo $24-57 \times 0,3-0,4 \mathrm{~cm}$, cilíndrico, amarelado a castanho-escuro, glabro distalmente e piloso na base, com tricomas semelhantes aos do caule; lâmina $22-40 \times 22-50 \mathrm{~cm}$, formando pares de pinas opostas, 2-muitas vezes furcadas, coriácea, glabra ou cerosa, gemas latentes na axila de cada bifurcação, cobertas por tricomas de 1-2,5 mm compr., septados, articulados, castanhoavermelhados; pinas 1-4-furcadas, com um par de pinas acessórias na base de cada furca, à exceção dos últimos ramos, pecioluladas, peciólulos, 3-10 $\times 0,1-0,2 \mathrm{~cm}$; pinas acessórias 3-14 × 2-3 cm, lanceoladas, pectinadas, pinatissectas a pinatífidas no ápice, sésseis; segmentos 0,2-1,5 cm larg., lanceolados, margem inteira ou revoluta. Soros na face abaxial dos segmentos, inframedianos, situados sobre as nervuras; esporângios globosos, subsésseis, agrupados em número de 2-5; esporos triletes.

Material examinado: BRASIL: Minas Gerais: Uberlândia, Estação Ecológica do Panga, VIII- 1986, M.A. Ranal 391 (HUFU); VII-1987, M.A. Ranal 477 (HUFU, SP); VI-1989, M.A. Ranal 537 (HUFU, SP); VII-1991, M.A. Ranal 550 (HUFU, SP); IV-1992, M.A. Ranal 556 (HUFU), M.A. Ranal 559 (HUFU, SP); III-1999, A.F. Amaral s.n. (HUFU19616), A.J.M. Guimarães s/n (HUFU26290); IX-2004, A.A. Arantes \& M.A. Ranal 1287 (HUFU, UC).

Espécie de ampla distribuição nas regiões quentes e úmidas no Novo Mundo (Sudeste dos Estados Unidos, Sul do México, América Central, Antilhas, Trinidad, Colômbia, Venezuela, Guiana, Suriname, Guiana Francesa, Equador, Peru, Bolívia, Paraguai e Brasil), porém rara em altitudes elevadas (Kramer 1978). No Brasil, ela é citada para as regiões norte, centro-oeste, nordeste, sul e sudeste (Barros \& Silva 2005). Na área de estudo Dicranopteris flexuosa é muito comum em locais abertos, em solo úmido, bordas de matas, trilhas, voçorocas e áreas alteradas.

Dicranopteris flexuosa difere das demais espécies da área pela presença de frondes pseudodicotômicas, com um par de pinas acessórias na base de cada pseudodicotomia, gemas axilares cobertas por tricomas septados, articulados e castanho-avermelhados.

Hymenophyllaceae Gaudich., Freyc. Voy. Bot.: 262. 1826; Link. Hand. Erkenn. Gew. 3: 36. 1833. 
Plantas terrestres, epífitas ou rupícolas. Caule delgado ou robusto, reptante ou ereto, protostélico. Frondes monomorfas ou raramente dimorfas; pecíolo não articulado ao caule, glabrescente a tomentoso; lâmina com tecido entre as nervuras formado por 1-2 camadas de células, estômatos ausentes, cutícula ausente ou reduzida; indumento com tricomas simples, furcados ou estrelados; soros marginais; indúsio cônico (campanulado), tubular ou bivalvado; receptáculo geralmente alongado, pelo menos nos gêneros tricomanóides, prolongado para fora do invólucro; esporângios com ânulos oblíquos e ininterruptos; esporos verdes, globosos, triletes.

O número de gêneros reconhecidos nesta família varia muito. De acordo com Smith et al. (2006), Hymenophyllaceae é monofilética e está constituída por nove gêneros, 600 espécies e dois grandes clados formados por espécies tricomanóides e himenofilóides (Pryer et al. 2001, Smith et al. 2006).

Os representantes desta família são plantas terrestres, rupícolas ou epífitas; essencialmente pantropicais e sul-temperadas. Lellinger (1994) cita a ocorrência de 220 espécies para os neotrópicos. Na área de estudo foi encontrada somente uma espécie, Trichomanes cristatum Kaulf.

Trichomanes L., Sp. Pl. 2: 1097. 1753. Lectótipo designado por Smith, Hist. Fil.: 347. 1875: Trichomanes scandens L.

Plantas epífitas, raramente terrestres ou rupícolas. Caule geralmente filiforme, longo-reptante, raro ereto, pubescente, com tricomas rígidos, raízes geralmente presentes. Frondes geralmente pequenas ou não, monomórficas, raro dimórficas, distantes entre si; pecíolo alongado, glabro ou piloso; lâmina inteira ou dividida, membranácea, geralmente translúcida, com uma camada de células de espessura, glabra ou pilosa, tricomas simples ou estrelados sobre as nervuras e margem; segmentos geralmente adnados e decorrentes próximos a raque; nervuras livres. Soros marginais, com um indúsio marginal cônico ou tubular, inteiro ou bilobado, imerso ou exserto; receptáculo geralmente forma um longo e exserto tricoma; esporos verdes, tetraédrico-globosos.

Trichomanes possui distribuição pantropical, com cerca de 320 espécies (Lellinger 1989), das quais 100 ocorrem nas Américas (Mickel \& Smith 2004).

Os dois gêneros que ocorrem no Brasil (Trichomanes e Hymenophyllum) são semelhantes por suas lâminas pequenas, membranáceas e soros marginais. Por outro lado, se diferenciam pelo tipo de indúsio bivalvado e receptáculo incluso em Hymenophyllum e, cônico ou tubular com receptáculo alongado em Trichomanes (Windisch 1996). Outras características também são muito importantes na taxonomia do grupo como a presença de falsas nervuras em algumas espécies de Trichomanes que, na verdade, são células colenquimatosas alongadas que aparecem como linhas finas entre as nervuras principais. Esta característica é usada para separar alguns subgêneros e espécies deste grupo (Lellinger 1989).

Trichomanes cristatum Kaulf., Enum. Filic. 265. 1824. Tipo: Brasil. Santa Catarina: Chamisso s.n. (holótipo LE, n.v.).

Figuras $1 \mathrm{H}-\mathrm{I}$

Plantas terrestres, ocasionalmente epífitas. Caule 0,3-0,7 cm diâm., curto-reptante, filiforme, piloso, tricomas de 1-3 mm compr., hirsutos, achatados, septados, castanho-avermelhados. Frondes 20-47 cm compr., monomorfas; pecíolo 3-10 × 0,1-0,15 $\mathrm{cm}$, mais espesso na base, castanho, coberto por tricomas semelhantes aos do caule, sulcado; lâmina 14-39 × 3,5-5,6 cm, linear-lanceolada, pinatissecta distalmente e pinatífida na porção apical, adaxialmente glabrescente a esparso pilosa sobre a costa, nervuras e margens, abaxialmente pilosas, tricomas aciculares, encurvados, 0,05-1,2 mm compr., articulados ou não, castanho-claros; raque não alada, pilosa nas duas faces; segmentos 2-2,6 × 0,4-0,6 cm, lineares, crenados, pinatilobados no ápice; nervuras livres, 1-5-furcadas, sem falsas vênulas. Soros 3-8 por segmento, mais freqüentes na porção apical da lâmina e nervuras; indúsio tubular, um por nervura, livre do tecido laminar.

Material examinado: BRASIL. Minas Gerais: Uberlândia, Estação Ecológica do Panga, VIII- 1986, M.A. Ranal 386 (HUFU, SP); II-1988, M.A. Ranal 504 (HUFU, SP).

Trichomanes cristatum é amplamente distribuída pela América tropical (Windisch 1996). No Brasil ocorre no Amazonas, Maranhão, Ceará, Mato Grosso, Minas Gerais, Rio de Janeiro, São Paulo, Paraná, Santa Catarina e Rio Grande do Sul (Labiak \& Prado 1998). Na E.E. Panga a espécie ocorre no interior de matas úmidas, tronco de árvores e margens de cursos d'água.

A espécie pode ser facilmente reconhecida pelos soros marginais, lâminas translúcidas, com uma 
só camada de células, indúsio tubular ou cônico e receptáculo alongado e exserto (figura 1I).

Lindsaeaceae C. Presl in M.R. Schomb., Reis. Br.Guiana 2: 883. 1848.

Plantas terrestres, rupícolas ou epífitas. Caule curto ou longo-reptante, protostélico ou solenostélico, com escamas lineares, não clatradas ou com tricomas aciculares. Frondes eretas ou escandentes, monomorfas ou raramente dimorfas; lâmina 1-4-pinada ou mais dividida, geralmente glabra; nervuras livres, furcadas, ocasionalmente anastomosadas, sem vênulas inclusas. Soros marginais ou submarginais, com indúsio abrindose em direção à margem, às vezes aderido às margens ou coberto pela margem dos segmentos; esporos tetraédricos, triletes, raro bilaterais, monoletes.

Representantes de três famílias (Dennstaedtiaceae, Cystodiaceae e Lonchitidiaceae) foram segregados em Lindsaeaceae no novo sistema de classificação (Smith et al.2006). A família Lindsaeaceae está composta por oito gêneros (Cystodium J. Sm., Lindsaea Dryand. ex Sm., Lonchitis L., Odontosoria Fée, Ormoloma Maxon, Sphenomeris Maxon, Tapeinidium (C. Presl) C. Chr. e Xyropteris K.U. Kramer) e cerca de 200 espécies com distribuição pantropical (Smith et al. 2006).

Lindsaeaceae está representada na E. E. do Panga por um gênero (Lindsaea) e duas espécies (Lindsaea pallida Klotzsch e Lindsaea quadrangularis Raddi).

Lindsaea Dryand. ex Sm., Mem. Acad. Roy. Sci. (Turin) 5: 413, pl. 9, f. 4. 1793.

Plantas terrestres, raro rupícolas ou epífitas. Caule horizontal, curto ou longo-reptante, com escamas lanceoladas, ovais a lineares. Frondes monomorfas, algumas vezes dimorfas; pecíolo castanho-amarelado, mais escuro em direção à base; lâmina inteira a 1-2(-4)-pinada, glabra; pinas e/ou pínulas dimidiadas, margem inteira; nervuras livres, furcadas ou anastomosadas, sem vênulas livres inclusas. Soros lineares, marginais ou submarginais, contínuos ou interrompidos, abaxiais, situados na confluência de duas ou mais nervuras; indúsio contínuo ou interrompido, abrindo em direção à margem da lâmina; esporângios glabros, com ânulo vertical ou levemente oblíquo, interrompido pelo pedicelo; paráfises presentes; esporos aclorofilados, amarelados, triletes ou monoletes.

Lindsaea é um gênero de distribuição pantropical e extratropical, com cerca de 150 espécies, das quais
45 ocorrem na América (Tryon \& Tryon 1982). Os caracteres distintivos do gênero são o pecíolo sulcado ou fortemente anguloso, pinas e/ou pínulas dimidiadas e soros submarginais. Estas características fazem com que as espécies deste gênero sejam confundidas com algumas espécies de Adiantum. No entanto, a raque e/ ou raquíola muitas vezes aladas e glabras de Lindsaea e o tipo de soros com indúsio abrindo-se em direção à margem são usados na distinção destes gêneros (Moran 1995d).

Chave para as espécies de Lindsaea da E.E. do Panga

1. Raque, raquíola e ápice do pecíolo quadrangulares; pecíolo castanhoescuro a castanho-avermelhado; indúsio crenado ou liso, não erodido ... L. quadrangularis

1. Raque, raquíola e ápice do pecíolo não quadrangulares; pecíolo castanhoclaro a esverdeado; indúsio serreado, erodido

L. pallida

Lindsaea pallida Klotzsch, Linnaea 18: 547. 1884. Tipo: Guiana Britânica, Schomburgk 1205 (holótipo B, n.v).

Figuras 2 A-D

Plantas terrestres. Caule 0,2-0,3 cm diâm., curto-reptante, com escamas de 1-1,5 mm compr., castanhas, linear-lanceoladas, clatradas. Frondes 35$55 \times 13-20 \mathrm{~cm}$ compr., monomorfas; pecíolo 16-26 $\times 0,1-0,2$ cm compr., castanho-claro a esverdeado e com escamas na base, escamas semelhantes às do caule, sulcado adaxialmente; lâmina 16-23 × 12-21 cm compr., 2-pinada, cartácea, lanceolada, rômbica a oblonga; pina 7-16 $\times 0,8-1,7 \mathrm{~cm}$ compr., curtopeciolulada, 3-6 pares; pínulas 0,5-0,7 $\times 0,4-0,5 \mathrm{~cm}$, dimidiadas, oblongas, curto-pecioluladas, geralmente laxas, glabras, margem acroscópica denteada, ápice arredondado; raque e raquíola sulcadas adaxialmente e cilíndricas abaxialmente; nervuras livres, 2-3furcadas. Soros margeando o lado acroscópico das pinas; indúsio de margem serreada, erodida; esporângios pedicelados; esporos monoletes.

Material examinado: BRASIL. Minas Gerais: Uberlândia, Estação Ecológica do Panga, X-2004, A.A.Arantes \& M.A. Ranal 1307 B (HUFU).

Lindsaea pallida possui distribuição restrita à América do Sul, ocorrendo na Colômbia, Venezuela, Trinidad, Guiana, Suriname e Brasil (Kramer 1957). A 


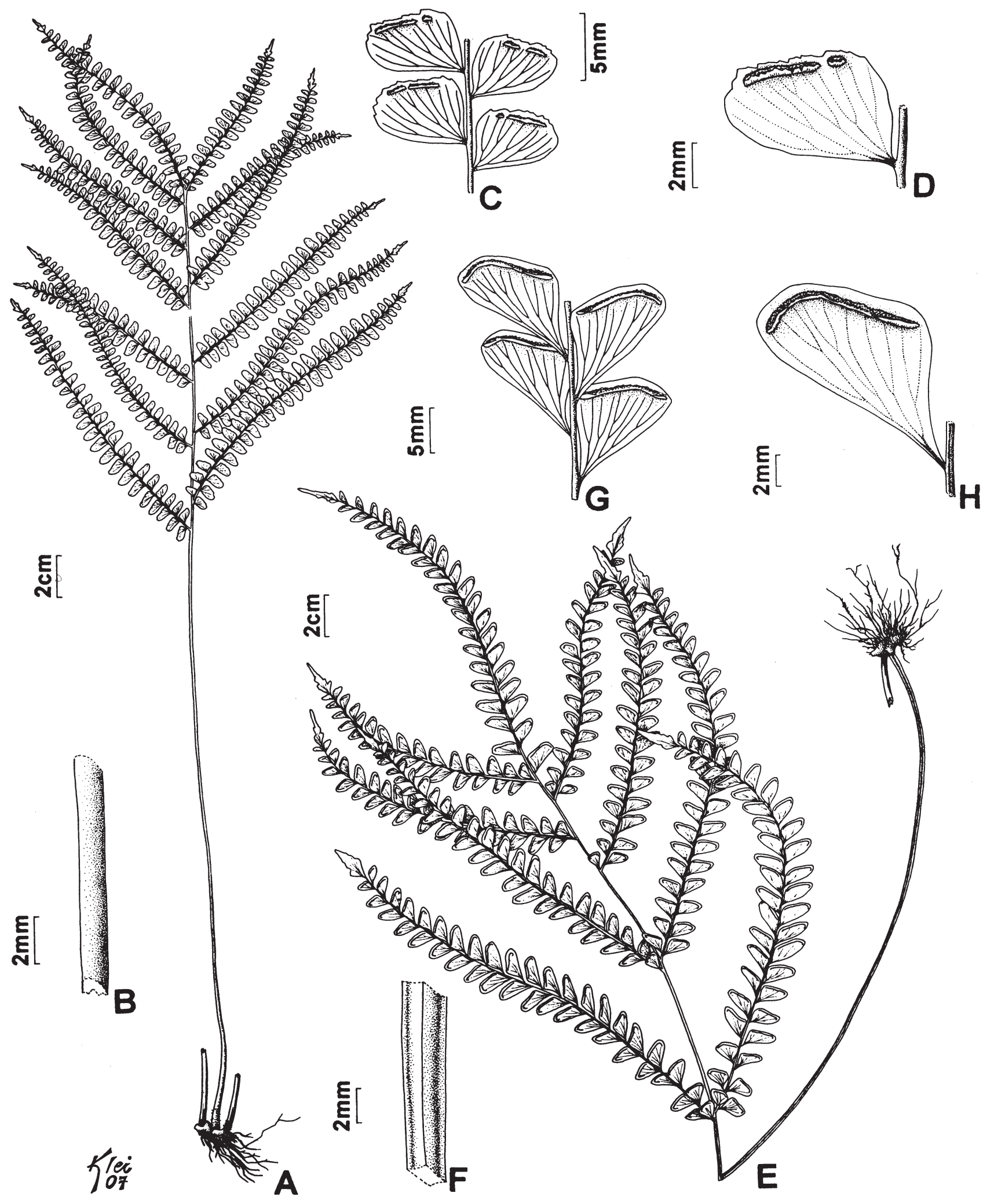

Figura 2. Espécies de Lindsaea da Estação Ecológica do Panga, Minas Gerais, Brasil. A-D. Lindsaea pallida (Arantes \& Ranal 1307B) A. Hábito. B. Detalhe da raque em face abaxial. C. Face abaxial da pina. D. Face abaxial de uma pínula. E-H. Lindsaea quadrangularis (Arantes \& Ranal 1251). E. Hábito. F. Detalhe da raque em face abaxial. G. Face abaxial da pina. H. Face abaxial de uma pínula. 
espécie é pouco coletada no Brasil, sendo citada para os Estados do Amazonas, Acre, Pernambuco, Bahia e Minas Gerais.

Lindsaea quadrangularis Raddi, Opusc.. Sci. 3: 294. 1819. Tipo: Brasil, Raddi s.n. (holótipo PI, n.v.).

Figuras 2 E-H

Plantas terrestres. Caule 0,4-0,6 cm diâm., curto-reptante, com escamas de 1-2,5 mm compr., castanhas, linear-lanceoladas, clatradas. Frondes 40$62 \times 15-22$ cm compr., monomorfas; pecíolo 22-30 × 0,3-0,4 cm compr., castanho-escuro e com escamas na base a castanho-avermelhado e glabro distalmente, quadrangular, sulcado nas duas faces; lâmina 15-22 cm compr., 2-pinada, cartácea, lanceolada, rômbica a oblonga, glabra; $1-7$ pares de pinas, pina 10-21 $\times$ 1,9-2,8 cm compr., as mais apicais menores e sésseis, lanceolada; pínula dimidiada, oblonga a trapeziforme, margens inteiras a crenadas, séssil a curto-peciolulada, peciólulo ca. $1 \mathrm{~mm}$ compr., pínula terminal livre, lanceolada, lobada; raque e raquíola quadrangulares, sulcadas nas duas faces; nervuras livres, 2-3-furcadas. Soros submarginais no lado acroscópico das pinas; indúsio linear de margem crenada ou lisa, não erodido; esporos triletes.

Material examinado: BRASIL. Minas Gerais: Uberlândia, Estação Ecológica do Panga, IX- 2004, A.A.Arantes \& M.A. Ranal 1251 (HUFU), 1286 (HUFU).

Espécie de distribuição ampla no continente americano, ocorrendo do México à Mesoamérica, Antilhas, Trindad, Colômbia, Venezuela, Suriname, Equador, Peru, Bolívia, Paraguai e Brasil (Tryon \& Tryon 1982). No Brasil é citada para quase todos os estados (Boldrin \& Prado 2007). Ocorre no interior de florestas, em solos arenosos, argilosos ou rochosos (Cremers \& Kramer 1991). Na E. E. do Panga foi encontrada em mata de galeria.

As duas espécies de Lindsaea da E. E. do Panga são muito semelhantes. Lindsaea quadrangularis difere de L . pallida pela raque e raquíola angulosas (quadrangulares) nas duas faces (figura 2F) e pínulas quase sempre trapeziformes (figura $2 \mathrm{G}-\mathrm{H}$ ), enquanto L. pallida difere da primeira por apresentar pínulas com margens acroscópicas denteadas e indúsio serreado a erodido (figura 2D).

\section{Agradecimentos}

Ao Dr. John T. Mickel, pela confirmação das identificações de Elaphoglossum.

\section{Literatura citada}

Alston, A.H.G. 1958. The Brazilian species of Elaphoglossum. Boletim da Sociedade Broteriana 2: 1-32.

Arantes, A.A., Prado, J \&. Ranal, M.A. 2008. Thelypteris subg. Amauropelta (Thelypteridaceae) da Estação Ecológica do Panga, Uberlândia, Minas Gerais, Brasil. Rodriguesia 59: 201-208.

Arantes, A.A., Ranal, M.A. \& Prado, J. 2007 a. Macrothelypteris e Thelypteris subg. Cyclosorus (Thelypteridaceae) da Estação Ecológica do Panga, Uberlândia, Minas Gerais, Brasil. Revista Brasileira de Botânica 30: 411-420.

Arantes,A.A.,Prado,J.\& Ranal, M.A.2007b. Thelypteris subg. Goniopteris e Meniscium (Thelypteridaceae) da Estação Ecológica do Panga, Uberlândia, Minas Gerais, Brasil. Hoehnea 34: 121-129.

Araújo, G.M., Barbosa, A.A.A., Arantes, A.A. \& Amaral, A.F. 2002. Composição florística de veredas no Município de Uberlândia, MG. Revista Brasileira de Botânica 25: 475-493.

Barros, I.C.L. \& Silva, M.R.P. 2005. Gleicheniaceae. In: T.B. Cavalcanti \& A.E. Ramos (orgs). Flora do Distrito Federal, Brasil, v. 4. Embrapa-Cenargem, Brasília, pp.147-157.

Boldrin, A.H.L. \& Prado, J. 2007. Pteridófitas terrestres e rupícolas do Forte dos Andradas, Guarujá, São Paulo, Brasil. Boletim de Botânica da Universidade de São Paulo 25: 1-69.

Cremers, G. \& Kramer, K.U. 1991. Dennstaedtiaceae. In: A.R.A. Görts-van Rijn (ed.). Flora of the Guyanas, series B: Ferns and fern allies, fasc. 4: 20-81.

Drummond, G.M., Martins, C.S., Machado, A.B.M., Sebaio,F.A.\& Antonini,Y.(orgs.). 2005. Biodiversidade em Minas Gerais: um atlas para sua conservação. 2 ed. Fundação Biodiversitas, Belo Horizonte.

Kramer, K.U.1957. A revision of the genus Lindsaea in the new World. Acta Botanica Neerlandica 6: 97-290.

Kramer, K.U. 1978. The pteridophytes of Suriname: Elaphoglossum. Uitgaven. Natuurwetenschappelijke Studiekring voor Suriname Nederlandse Antillen 93: 1-198.

Kramer, K.U. 1990. Lomariopsidaceae. In: K. Kubitzki (ed.). The families and genera of vascular plants. In: K.U. Kramer \& P.S. Green (eds.). Pteridophytes and Gymnosperms. Springer-Verlag, Berlin, v. 1, pp. 164170. 
Labiak, P. H. \& Prado, J. 1998. Pteridófitas epifíticas da Reserva Volta Velha, Itapoá - Santa Catarina, Brasil. Boletim de Botânica da Universidade de São Paulo 11: 1-79.

Lellinger, D.B. 1989. The ferns and fern-allies of Costa Rica, Panama, and the Chocó. Part 1: Psilotaceae through Dicksoniaceae. Pteridologia 2A: 1-364.

Lellinger, D.B. 1994. Trichomanes polypodioides and its allies. American Fern Journal 81: 24-37.

Lellinger, D.B. 2002. A modern multilingual glossary for taxonomic pteridology 3. American Fern Society, Washington, D.C.

Meira Neto, J.A.A. 2003. A política de conservação da diversidade vegetal nos cerrados de Minas Gerais. In: M.A.G. Jardim, M.N.C. Bastos \& J.U.M. Santos (eds.). Desafios da Botânica no novo milênio: Inventário, sistematização e conservação da diversidade vegetal. Embrapa, Museu Paranaense Emílio Goeldi, Belém.

Mendonça, R.C., Felfili, J.M., Walter, B.M.T., Silva Júnior, M.C., Rezende, A.V., Filgueiras, T.S. \& Nogueira, P.E. 1998. Flora Vascular do Cerrado. In: S.M. Sano \& S.P. Almeida (eds). Cerrado: Ambiente e Flora. Embrapa - CPAC, Planaltina, pp. 289-556.

Mickel, J. \& Smith, A.R. 2004. The Pteridophytes of Mexico. Memoirs of the New York Botanical Garden 88: 1-1070.

Moran, R.C. 1995a. The importante of mountains to pteridophytes, with emphasis on neotropical montane forests. In: S.P. Churchill, H. Balslev, E. Forero \& J.L. Luteyn (eds.). Biodiversity and Conservation of Neotropical Montane Forests. The New York Botanical Garden, New York, pp. 359-396.

Moran. R.C. 1995 b. Pteridium. In: R.C. Moran \& R. Riba (eds.). Psilotaceae a Salviniaceae. In: G. Davidse, M. Sousa \& S. Knapp (eds.). Flora Mesoamericana, Universidad Nacional Autónoma de México, Ciudad de México, v. 1, pp. 161-162.

Moran, R.C. 1995c. Lomariopsidaceae. In: R.C. Moran \& R. Ribas (eds.). Psilotaceae a Salviniaceae. In: G. Davidse, M. Souza \& S. Knapp. (eds.). Flora Mesoamericana. Universidad Nacional Autónoma de México, Ciudad de México, v. 1., pp. 247-285.

Moran, R.C. 1995d. Lindsaea. In: R.C. Moran \& R. Riba (eds.). Psilotaceae a Salviniaceae. In: G. Davidse, M. Souza \& S. Knapp. (eds.). Flora Mesoamericana. Universidad Nacional Autónoma de México, Ciudad de México, v. 1., pp. 157-159.
Pichi-Sermolli, R.E.G. 1996. Authors of scientific names in Pteridophyta. Royal Botanic Gardens, Kew.

Prado, J. 2007. As Pteridófitas ameaçadas de extinção no Estado de São Paulo. In: M.C.H. Mamede, V.C. Souza, J. Prado, F. Barros, M.G.L. Wanderley \& J.G. Rando. (orgs.). Livro Vermelho das espécies ameaçadas de extinção no Estado de São Paulo. Instituto de Botânica, São Paulo, pp. 39-45.

Pryer, K.M., Schneider, H., Smith, A.R., Cranfill, R., Wolf, P.G., Hunt, J .S. \& Sipes, S.D. 2001. Horsetails and ferns are a monophyletic group and the closest living relatives to seed plants. Nature 409: 618-622.

Pryer, K.M., Schuettpelz, E., Wolf, P.G., Schneider, H., Smith, A.R. \& Cranfill, R. 2004. Phylogeny and evolution of ferns (Monilophytes) with a focus on the early leptosporangiate divergences. American Journal of Botany 91: 1582-1598.

Ranal, M.A. 2003. Soil spore bank of ferns in a gallery forest of the Ecological Station of Panga, Uberlândia, MG, Brazil. American Fern Journal 93: 97-115.

Ribeiro, J.F. \& Walter, B.M.T. 1998. Fitofisionomias do bioma cerrado. In: S.M. Sano \& S.P. Almeida (eds). Cerrado: ambiente e flora. EMBRAPA - CPAC, Planaltina, pp.89-168.

Roos, M. 1996. Mapping the world's pteridophyte diversity - systematics and floras. In: J.M. Camus, M. Gibby \& R.J. Johns (eds). Pteridology in perspective. Royal Botanic Gardens, Kew, pp. 29-42.

Salino, A. 2000. Pteridófitas. In: M.P. Mendonça \& L.V. Lins (orgs.). Lista Vermelha das espécies ameaçadas de extinção da flora de Minas Gerais. Fundação Biodiversitas e Fundação Zôo-Botânica de Belo Horizonte, Belo Horizonte, pp. 97-103.

Smith, A.R., Pryer, K.M., Schuettpelz, E., Korall, P., Schneider, H. \& Wolf, P.G. 2006. A classification for extant ferns. Taxon 55: 705-731.

Tryon, R.M. 1986. The biogeography of species, with special reference to ferns. The Botanical Review 52: 117-155.

Tryon, R.M. \& Tryon, A.F. 1982. Ferns and allied plants, with special reference to tropical America. SpringerVerlag, New York.

Windisch,P.G. 1992. Pteridófitas da região Norte-ocidental do Estado de São Paulo (Guia para estudo e excursões). 2 ed. UNESP, São José do Rio Preto.

Windisch, P.G. 1996. Pteridófitas do Estado do Mato Grosso: Hymenophyllaceae. Bradea 6: 400-423. 